\title{
Gender Differences in Motor Coordination at Young Students at Psychology
}

\author{
Mihaela Chraif and Mihai Aniței
}

\begin{abstract}
The research highlights gender differences in motor coordination on visual task. The method: Participants were 68 students at Faculty of Psychology and Educational Sciences, University of Bucharest, Romania, 36 female and 32 male, aged between 18 and 23 years old $(m=21.38 ; S . D .=1.72)$. The instruments: Two hand coordination test from Vienna Tests System. Results highlight that young female students have the ability to calibrate, correct the errors and to learn from errors statistically significant than young male students and the young male students are statistically significant more precisely in competing the task.
\end{abstract}

Index Terms-Gender differences, motor coordination, visual task, alphabetical order, commas.

\section{INTRODUCTION}

Sensory-motor coordination represents an important research objective among specialists. Coordination associating at least one motor system has always been invested in gender differences with a major role in cognitive development. Eye-hand coordination is the coordinated control of eye movement with hand movement. In other words, eye-hand coordination and hand-eye coordination imply the execution of a task. It is involved in various routine activities, from simple preparation of tea, to moving solid objects, performance sports or computer games. Coulometer coordination is particularly important in the life of an individual as it is a way to successfully perform most activities and its absence may result in failure to achieve even the simplest action. Researchers have conducted several studies on the implications of visual-motor coordination of human behavior. [1] Highlighted that gaze is fixed on a target object, before beginning hand movement, indicating that the eyes provide information about distance to the arms. Previous studies evidenced that the average male performance in spatial tasks is better than that females [2], determined by biological and cultural explanations as [3] investigated. [4] Highlighted that men are better than women at visual-motor coordination, because their usual operating environment, engaging in activities that require these abilities. Furthermore, the same authors show that males are encouraged to practice contact sports and get toys developing

Manuscript received December 10, 2012; revised February 18, 2013.

M. Anitei is with the Doctoral School, Coordinator of Experimental Psychology Laboratory Faculty of Psychology and Educational Sciences, University of Bucharest, President of Collegium of Psychologists, Romania, IEDRC member (e-mail: anitei_mihai@yahoo.com).

M. Chraif is with the Work and Transportation Psychology Laboratory, Coordinator of Master program "Management of training psychologists in work, transportation and services psychology" Faculty of Psychology and Educational Sciences, University of Bucharest, Romania (e-mail: mihaelapopa14@yahoo.com). hand-eye coordination during childhood. [5] Using physical practice tasks, underlined found an improvement in eye-hand coordination ability in both female and male participants. The authors show that during computer testing, males obtained better performance than women. Furthermore, after practicing a period of time, women significantly improved their scores to testing. [6] Found that there are significant differences in the ability of coordination between women and men by age. Furthermore, [7] highlighted significant gender differences when the groups were formed by older participants. Previous research conducted in the Laboratory of Experimental Psychology have shown differences in performing cognitive and sensory-motor tasks under the influence of noise radio [8], memory and attention capacity as affected by sleep deprivation among young individuals [9], in visual perception evaluation and in timed cognitive tasks observed during psychological testing for driving license of young individuals [10].

\section{OBJECTIVE AND HYPOTHESES}

\section{A. Objective}

To highlight gender differences in motor coordination during two hand coordination visual computerized task.

\section{B. General Hypothesis}

There are statistically significant gender differences in young students' motor coordination at two hand coordination visual computerized task.

\section{Specifically Hypotheses}

There are statistically significant differences between male and female at overall mean duration in young students.

There are statistically significant differences between male and female at overall mean error duration in young students.

There are statistically significant differences between male and female at overall percent duration in young students.

\section{METHOD}

\section{A. Participants}

The participants were 68 students from the Faculty of Psychology and Educational Sciences, University of Bucharest, 36 female and 32 male, aged between 18 and 23 $(m=21.38 ;$ S.D. $=1.72)$.

\section{B. Instruments}

Motor coordination test, Vienna Tests System, [11] cited by [12], [13]. The test measures the speed and accuracy of coordination when making fine, small movements. The task 
is to move a red spot along a gray track. The task can be completed either with two control knobs or two joysticks. According to the test handbook this test focuses on two aspects of human ability: eye-hand coordination and coordination between the left and right hand [11].

Fig. 1 presents the task of modeling the red spots' trajectory along the gray track.

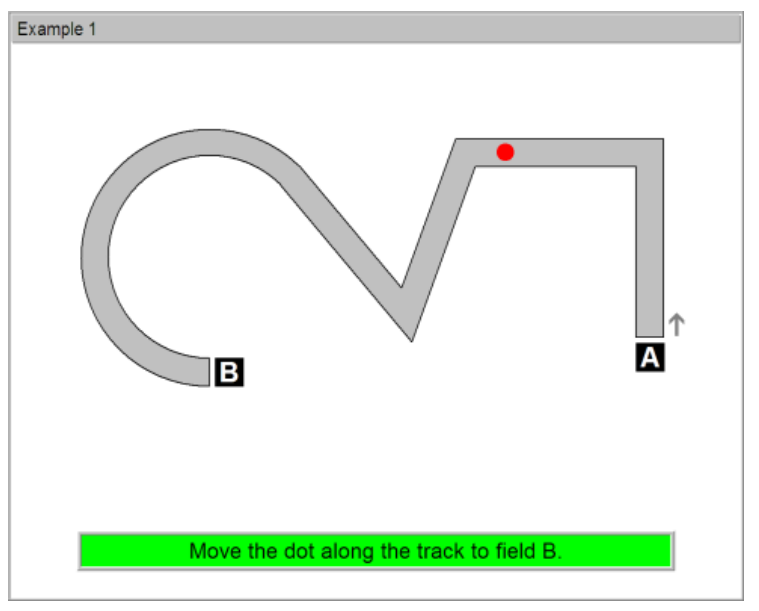

Fig. 1. Example of item from two hand coordination test [11].

In Fig. 2 can be seen an example of item situation from Two hand coordination test.

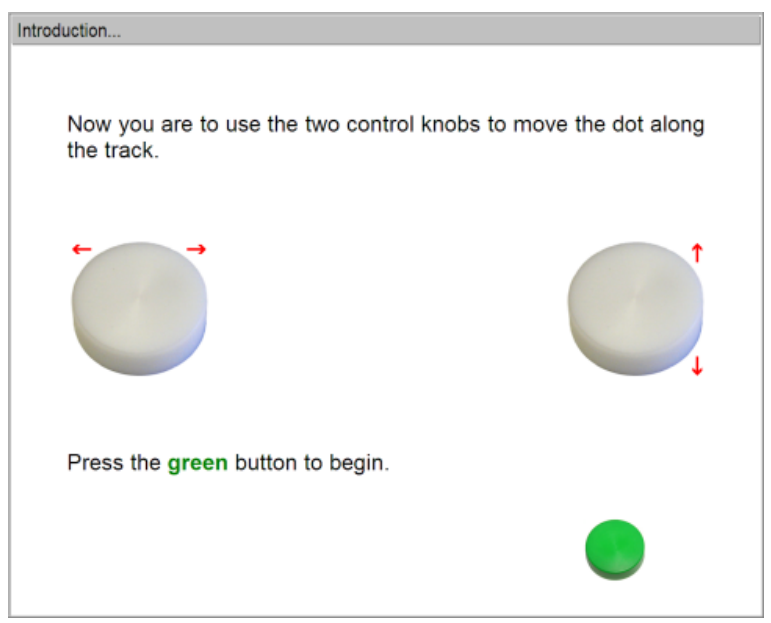

Fig. 2. Control Knobs used in two hand manipulation of the red track in the grey tunnel (Fig. 1) [11]

\section{Procedure}

Participants are introduced to the isolated laboratory area where they can complete two hand coordination tests. The test shows objective written instructions and has no time limit to be completed.

\section{Variables}

Independent variable [14] is the participant's gender.

Dependent variables [14] are:

- Overall mean duration. This variable is the average time taken to move the red spot along the track. It measures the speed of movement and the respondent's performance level. A high score indicates that the respondent is able to convert the information about the position of the red spot into appropriate fine movements.

- Overall mean error duration: This variable represents the time (summed over all runs) during which the point was outside the tolerance limit defined by the track area.

- Overall percent duration: represents the ratio of the total error duration to the total duration. Hence, above average score indicates that the respondent is very good at converting very small deviations from the intended route into appropriate compensatory movements.

\section{RESUlts}

Before calculating the difference between the two experimental groups using the t-test, the Kolmogorov-Smirnov test was used to verify the normality of data distribution for the variables of each of the three groups [12]. Thus, the Overall Mean Duration Variables (pfemale $=0.548>0.05 ;$ pmale $=0.350)$, Overall Mean Duration Error $($ pfemale $=0.559>0.05$; pmale $=0.747$ ), Overall Duration Percent (pfemale $=0.806>0.05$; pmale $=$ $0.465)$ data distributions are normally distributed. Hence, the t-test for differences between groups was applied.

\begin{tabular}{llccc}
\multicolumn{4}{c}{ TABLE I: THE ARRANGEMENT OF CHANNELS } \\
\hline \hline Variables & Groups & N & Mean & $\begin{array}{c}\text { Std. } \\
\text { Deviation }\end{array}$ \\
\hline $\begin{array}{l}\text { overall mean } \\
\text { duration }\end{array}$ & female & 36 & 70.30 & 13.59 \\
$\begin{array}{llll}\text { overall mean } \\
\text { error duration }\end{array}$ & male & 32 & 58.00 & 14.25 \\
& female & 36 & 72.41 & 15.32 \\
$\begin{array}{l}\text { overall percent } \\
\text { duration }\end{array}$ & female & 32 & 58.78 & 14.29 \\
& male & 32 & 71.62 & 16.30 \\
\hline \hline
\end{tabular}

Table I shows the descriptive statistics for the variables measured by the "two hand coordination" task. In table II the t-test value and p-value for mean groups' differences (female and male) can be seen.

TABLE II: THE ARRANGEMENT OF CHANNELS

\begin{tabular}{clccc}
\hline \hline Variables & Groups & $\mathbf{N}$ & $\begin{array}{c}\text { t-test } \\
\text { value }\end{array}$ & $\begin{array}{c}\text { p-valu } \\
\mathbf{e}\end{array}$ \\
\hline $\begin{array}{c}\text { Overall Mean } \\
\text { Duration }\end{array}$ & female & 36 & 3.64 & 0.001 \\
male & 32 & & \\
Overall Mean & female & 36 & 3.78 & 0.000 \\
Error Duration & male & 32 & & \\
Overall Percent & female & 36 & 2.77 & 0.007 \\
Duration & male & 32 & & \\
\hline \hline
\end{tabular}

Hence, the initial hypotheses have been confirmed as follows: The first hypothesis "There are statistically significant differences between male and female at overall mean duration in young students" has been confirmed to be statistically significant $(t=3.64 ; p=0.001<0.01)$ and the mean of the variable "overall mean duration" was statistically significant higher for the female students than male students $(70.3>58.00)$. The second hypothesis "There are statistically significant differences between male and female at overall mean error duration" has been confirmed to be statistically significant $(t=3.78 ; p=0.0001<0.01)$ and the mean of the 
variable "overall percent duration" it was statistically significant higher for the female students than male students (72.41>58.78). Also the third hypothesis has been confirmed to be statistically significant $(t=2.77 ; p=0.007<0.01)$. "There are statistically significant differences between male and female students at overall percent duration" and the mean of overall percent duration was also statistically significant higher for the female young students (71.62>61.28).

\section{CONCLUSION}

A Based on previous research on gender differences in cognitive tasks [2], [9] and those of sensory motor coordination [6], [7] this research revealed gender differences in visual motor coordination and ability to perform calibration and rehabilitation tasks. By confirming the second hypothesis the research highlighted that young female students have shown a higher capacity for rehabilitation and calibration of the red spot moving from outside border to inside grey task line than male students. A high score of the variable "Overall mean duration" indicates that the respondent is able to convert the information about the position of the red spot into appropriate fine movements. Hence, statistically significant differences evidenced that young female students have a higher level of precision than young male students $(t=3.64, p=0.001<0.01)$.

The variable "Overall mean duration error" represents the time during the moment when the point was outside the tolerance limit (defined by the grey track area) and getting back to the grey track line. Hence, these results were statistically significant higher for the young female students compared to the young male students $(t=3.64, p=0.001$ $<0.01)$. These findings, supported by previous research, highlight that young males are more precisely hand-eye coordinated than young female students statistically significant higher. Furthermore, these findings highlight that young female students have a higher ability to calibrate, correct and learn from errors than young male students statistically significant higher $(t=2.77, p=0.007<0.01)$.

\section{ACKNOWLEDGMENT}

This work was supported by the strategic grant POSDRU/89/1.5/S/62259, Project "Applied social, human and political sciences. Postdoctoral training and postdoctoral fellowships in social, human and political sciences", is co-financed by the European Social Fund within the Sectorial Operational Program Human Resources Development 2007-2013.

\section{REFERENCES}

[1] R. S. Johannson, G. Westling, A. Backstron, and J. R. Flanagan, "Eye-hand co-ordination in object manipulation," Journal of Neuroscience, vol. 21, no. 17, pp. 6917-6932, 2001.

[2] D. F. Halpern, Sex Differences in Cognitive Abilities, 3rd Edition, Mahwah, NJ: Lawrence Erlbaum Associates, 2000.

[3] D. Voyer, S. Voyer, and M. Bryden, "Magnitude of sex differences in spatial abilities: A meta-analysis and consideration of critical variables," Psychological Bulletin, vol. 117, pp. 250-270, 1995.

[4] M. Baenniger and N. Newcombe, "The role of experience in spatial test performance: A meta-analysis," Sex Roles, vol. 20, pp. 327-345, 1989.
[5] D. P. Saccuzzo, A. S. Craig, N. E. Johnson, and G. E. Larson, "Gender differences in dynamic spatial abilities," Personality and Individual Differences, vol. 21, pp. 599-607, 1996.

[6] K. Kauranen and H. Vanharanta, "The infuence of aging, gender and handedness on motor performance of upper and lower extremities," Percept Mot Skills, vol. 82, pp. 515-525, 1996.

[7] M. Ruff and S. B. Parker, "Gender-and-age-specific change in motor speed and eye-hand coordination in adults: Normative values for the finger tapping and grooved pegboard tests," Perceptual and Motor Skills, vol. 76, pp. 1219-1230, 1993.

[8] M. Chraif, "The effects of radio noise in multiple time reaction tasks for young students," in Procedia Social and Behavioral Sciences, Elsevier, vol. 33, pp. 1057-1062, 2012.

[9] M. Chraif, "The influence of sleep deprivation on short term memory and attention to details in young students," in Procedia Social and Behavioral Sciences, Elsevier, vol. 33, pp. 1052-1056, 2012.

[10] M. Chraif and M. Aniței, "Evaluation based on stereoscopic vision test within driving schools assessment centre," in Procedia of International Conference on Humanity, History and Society - ICHHS, pp. 58-64, 2012.

[11] Vienna Test System Psychological Assessment catalog, 2012.

[12] M. Chraif, Experimental Psychology, Bucharest: Editura Renaissance, 2012.

[13] M. Aniței, S. Trifu, and M. Chraif, Student's Guide for Practical Activities in Psychology, Bucharest: Ed Universitară, 2010.

[14] M. Aniței, Experimental Psychology, Iaşi: Polirom, 2007.

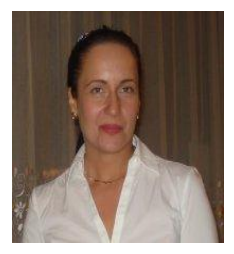

M. Chraif was born in Romania on February 14, 1974 She graduated Faculty of Psychology (2007-Faculty of Psychology and Educational Sciences, University of Bucharest) and Faculty of Economics, Financing and Accounting (2002- Titu Maiorescu University, Bucharest Romania) and also she graduated three masters programs: 1) Master in Financing and Capital Markets-2002-2004, Academy of Economic Sciences, Bucharest Romania; 2) Master in Organizational Psychology and human resources, University of Bucharest, Romania; 3) Clinical psychology and Cognitive behavioural psychotherapy, Titu maiorecu University, Bucharest, Romania. Also, she took her $\mathrm{PhD}$ in Cognitive Psychology applied to workplace and transportation psychology in 2009, Bucharest University, Romania. Since then she has constantly been working in the field teaching, research studies at the Faculty of Psychology and Educational Sciences, University of Bucharest. Since 2010 she is postdoctoral fellow in the strategic grant POSDRU/89/1.5/S/62259, E.U. Project. She is coordinator of master degree dissertations. Also she has the followings attributes: Coordinator of the Master's Degree program:"Work and Transport Psychology", Coordinator of Work and Transportation Psychology Laboratory, Faculty of Psychology and Educational Sciences, University of Bucharest, Romania. She wrote 9 books and more than 100 research papers and scientific studies published at International Conferences, Proceedings, National Conferences and International and National Journals. The author published the main Current and previous research interests are the following: psychophysiology measured by polygraph, EEG studies, experimental psychology, changing behavior in different fields: traffic, work and organizational psychology, educational psychology, clinical psychology, stocks, financing. Lecturer PhD M. Chraif has the following memberships: IEDRC, Romanian Collegium of Psychologists, the Romanian Society of Work, Organizational and traffic Psychology, the Romanian Society of Experimental Applied Psychology, Romanian Association of Integrative Psychotherapy.

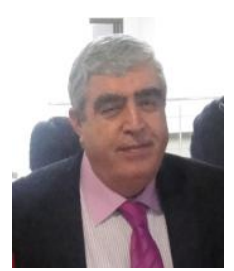

M. Aniței was born in Romania on October 18, 1948 He graduated Faculty of Psychology and Educational Sciences in 1974. He took his PhD in Psychology in 1990. Mr. Aniței has the following degree: bachelor's degree and master's degree paper coordinator; president of the $\mathrm{Ph} . \mathrm{D}$ paper analysis committee; postdoctoral program coordinator at Faculty of Psychology and Educational Sciences, University of Bucharest. The author's 
major fields of study are the following: Experimental Psychology, Traffic Psychology, Cognitive Psychology, Organizational Psychology, Emotions, Cognition and Behavior, Management of Human Resources, Clinical Psychology, Environmental Psychology and Consumer behaviour Psychology. He is the President of the Collegium of the Psychologists from Romania and the director of the Doctoral School, Faculty of Psychology and Educational Sciences, University of Bucharest. Also he has the followings attributes: Director of Doctoral School, Faculty of Psychology, University of Bucharest, He wrote 8 books and more than 100 research papers and scientific studies published international conferences, Proceedings, national conferences and International and National Journals. Professor PhD M. Aniței has the following memberships: IEDRC, Romanian Collegium of Psychologists, the Romanian Society of Work, Organizational and traffic Psychology, the Romanian Society of Experimental Applied Psychology. 